\title{
Ruminant Eructation and a Long-Run Environmental Kuznets' Curve for Enteric Methane in New Zealand: Conventional and Fuzzy Regression Analysis
}

\author{
David E.A. Giles \\ \& \\ Carl A. Mosk \\ Department of Economics, University of Victoria \\ Victoria, B.C., Canada V8W $2 Y 2$
}

June, 2003

\begin{abstract}
This paper examines the very long-run relationship between income and emissions of enteric methane in New Zealand, over the period 1895 to 1996. Controlling the emissions of this particular greenhouse gas is of crucial importance if that country is to meet its obligations as a signatory to the Kyoto Protocol. We use standard parametric regression, nonparametric regression, and a new nonlinear regression estimator based on fuzzy clustering analysis, to estimate 'environmental Kuznets' curves' for $\mathrm{CH}_{4}$ in New Zealand. Our results appear to be the first to support the existence of some form of 'inverted-U' curve for this pollutant, and the 'double-hump' relationship that emerges from our fuzzy modeling is consistent with certain theoretical results. Methane pollution is maximized at a level of real per capita GDP that is consistent with those reported for other pollutants in the literature.
\end{abstract}

JEL Classifications: C14; C49; C51; O1; Q2

Keywords: $\quad$ Environmental Kuznets' curve; fuzzy regression; greenhouse gas; Kyoto Author Contact: Protocol; methane emissions; sheep

Professor David E.A. Giles, Department of Economics, University of Victoria, P.O. Box 1700, STN CSC, Victoria, B.C., Canada V8W 2Y2; email: dgiles@uvic.ca; Voice: (250) 721-8540; FAX: (250) 721-6214 


\section{Introduction}

Globally, methane $\left(\mathrm{CH}_{4}\right)$ is an important greenhouse gas (GHG), estimated by the International Panel on Climate Control (IPCC) to account for $20 \%$ of the global radiative forcing due to increases in atmospheric concentrations of GHG's since 1750. In current terms, it is the second most important GHG, after carbon dioxide. New Zealand is a 'small player' in the international pollution arena, producing less than $0.5 \%$ of the world's $\mathrm{CH}_{4}$, but it has a unique GHG emissions profile among developed countries. ${ }^{1}$ Specifically, over $50 \%$ of New Zealand's recent anthropogenic emissions are attributable to $\mathrm{CH}_{4}$, in terms of $\mathrm{CO}_{2}$-equivalent units. Moreover, in this country of 45.7 million sheep, 4.4 million dairy cattle, and 4.6 million beef cattle (and 3.7 million people, 1999 figures) enteric $\mathrm{CH}_{4}$ accounts for $88 \%$ of all methane emissions, and $99 \%$ of $\mathrm{CH}_{4}$ emissions from just the agricultural sector. ${ }^{2}$ New Zealand's economic history has been dominated by sheep since the establishment of the first sheep station in that country in 1844 . While only recently of public concern, emissions of $\mathrm{CH}_{4}$ have existed, and have inhibited wool and meat production since then, and they warrant a long-term analysis.

New Zealand is a signatory to the United Nations Framework Convention on Climate Change (FCCC), and to the Kyoto Protocol. Accordingly, it has a commitment to prepare accurate inventories of its sources and sinks for all GHG's, and during the period 2008-2012 New Zealand is also committed to limiting its levels of GHG's to their 1990 level. ${ }^{3}$ Not surprisingly, therefore, the role of enteric $\mathrm{CH}_{4}$ is crucial to these calculations and to the associated environmental policy debate in that country. Enteric methane production is the output of $\mathrm{CH}_{4}$ from ruminants - sheep, dairy cows, beef cattle and farmed deer and goats in the case of New Zealand. It is essentially a by-product of the rumen fermentation process, and the methane is released into the atmosphere primarily when these animals engage in eructation (i.e., they belch excessively)!

Recent agricultural research in New Zealand has focused on obtaining direct, 'on the farm' measurements of this interesting activity, and also on the role and relative importance of pasture type, climatic and seasonal factors. Consequently, several mitigation options have been isolated, these focusing on the manipulation of enteric bacteria by various means. The objective is not only to reduce total $\mathrm{CH}_{4}$ emissions, but also to improve animal productivity - enteric methane production requires energy that can otherwise be used by the animal to produce meat, wool or milk. $^{4}$ 
The following developments are among those that are pertinent to the GHG problem in New Zealand. $\mathrm{CO}_{2}$ emissions have grown by about $20 \%$ since 1990 , primarily in association with growth in the electricity generation and transportation sectors. By way of partial compensation, although the annual planting rate of forest sinks decreased during the 1990's, it has now returned to about its 1990 rate. Sheep numbers declined steadily from a peak of 70.3 million in 1982 to approximately 57.9 million in 1990, and by $21 \%$ between 1990 and 1999. In contrast, however, dairy and beef cattle numbers have increased by $25 \%$, and $1 \%$ respectively since 1990 , and the number of farmed deer has risen by $72 \%$. These significant changes in the both the numbers and the 'mix' of ruminants, coupled with their vastly different $\mathrm{CH}_{4}$ emission rates, complicate the task that New Zealand scientists and policy-makers face in order to meet their Kyoto Protocol obligations. ${ }^{5}$

Our objective is to explore the very long-run relationship between income and enteric $\mathrm{CH}_{4}$ emissions in New Zealand. Specifically, we ask, 'Is there an environmental Kuznets' curve' for this particular GHG in New Zealand?' Given the mixed international empirical evidence associated with environmental Kuznets' curves, and the special role of methane in New Zealand, there is a strong case for analyzing this individual GHG, rather than considering a more general index of pollutants. It is estimated that the agricultural sector contributes approximately $17 \%$ of New Zealand's GDP. ${ }^{6}$ In 1999 44.1\% of that country's export revenues were 'pastoral based' and hence dependent on ruminants. 'Solving' the GHG problem, and meeting the Kyoto Protocol targets simply by dramatically reducing the numbers of these animals is not a viable option from an economic perspective for reasons that we discuss in detail below. A better understanding of the trade-off between methane emissions and economic output is certainly helpful to the current environmental policy debate in New Zealand, and elsewhere. In the next section we summarize some of the relevant literature relating to research on environmental Kuznets' curves. Section 3 deals with data construction issues associated with our use of time-series spanning just over a century; and in section 4 we outline the modelling techniques that we use. The main empirical results, which include strong new evidence of an environmental Kuznets' curve for enteric methane, are presented in section 5; and section 6 discusses the role of trade and some policy implications. The paper concludes with a section that summarizes our principal findings. 


\section{Environmental Kuznets' Curves}

Kuznets (1955) proposed that there is an 'inverted-U' relationship between income inequality and a country's level of output. The basis for this was that if income inequality between high productivity and low productivity sectors in the economy is higher than inequality within each sector, then income inequality should rise, at first, as people moved between sectors. Then it should fall as this flow of labour ended, or when returns to the factors of production were balanced across the sectors. He supported this hypothesis with the analysis of time-series data for the United Kingdom, the U.S.A. and Germany. Numerous studies have since explored Kuznets' proposal, with rather mixed results. In particular, the empirical results that have been obtained have depended to some degree on the overall level of development of the countries in question, the type of data (namely, time-series or cross-country) that have been used, and the extent to which other factors have been taken into account. With the availability of larger and richer datasets, the more recent literature has generally discounted Kuznets' hypothesis (e.g., Deininger and Squire, 1998). ${ }^{8}$ It should also be emphasized that even when a statistically robust Kuznets' relationship can be established, it does not imply anything about causality from inequality to income, or vice versa. It simply suggests that rising income is associated with a worsening, and then an improvement, in income inequality.

There is now a well-established literature, dating back at least to the World Bank (1992) and Grossman and Krueger (1991, 1995), that explores the possibility of a so-called 'environmental Kuznets curve' (EKC) - that is, an 'inverted-U' shaped relationship between environmental

pressure and per capita income. ${ }^{9}$ There is a certain amount of theoretical support in favour of the existence of an EKC - that is, a worsening and then an improvement in pollution as income rises. For example, Andreoni and Levinson (1998) present a static model that shows that an EKC can be derived from the technological link between consumption of a desired good and the abatement of its undesirable by-product. Pfaff et al. (2001) provide a theoretical framework at the household level, and by focusing on the linkage between income and household choices that impact upon the environment, they show how household-level EKC's can arise. Other theoretical contributions include those of Selden and Song (1995) and Stokey (1998). For example, the former authors note that among the factors that lead to an initial increase, and subsequent downturn in pollution as income grows are: (i) positive income elasticities for environmental quality; (ii) changes in the composition of production and consumption; (iii) increasing levels of education and awareness; (iv) more open political systems. ${ }^{10}$ On the other hand, Bousquet \& Favard (2000) develop a 
public good model of the provision of environmental quality with 'bell-shaped' income inequality, and they show that their model generates an 'environmental camel curve' - a curve with 'two humps'.

Interestingly, this last theoretical result is consistent with the recent empirical results of Taskin and Zaim (2000). Using nonparametric production frontier methods and aggregate data for 52 countries over 16 years, they estimate an $\mathrm{EKC}$ for $\mathrm{CO}_{2}$ emissions with a peak, followed by a trough, as real per capita GDP increases. Their results are also quite compatible with those of Dijkgraaf and Vollebergh (2001). They use a panel of data for OECD countries between 1960 and 1997, and for certain countries the $\mathrm{CO}_{2}$ data follow the pattern established by Taskin and Zaim, a point to which we will return below. As a result of their econometric analysis they conclude that it is unlikely that the overall income-emission relationship is of the 'inverted-U' type. The (relatively) early results of Selden and Song (1994) uncovered EKC's for $\mathrm{SO}_{2}, \mathrm{CO}$, oxides of nitrogen $\left(\mathrm{NO}_{\mathrm{x}}\right)$ and suspended particulate matter (SPM). Other early contributions include those of Shafik (1994), Shafik and Bandyopadhyay (1992) and Holtz-Eakin and Selden (1995), and Hilton and Levinson (1998) provide a tabular summary of the various results that favour the EKC.

The EKC hypothesis has been widely criticized both on conceptual grounds and empirically (e.g., Ekins, 1997, and Stern et al., 1997). Although there appears to be some evidence of EKC's for certain pollutants with short term effects and low abatement costs (e.g., $\left.\mathrm{SO}_{2}\right)$, the same is not true in general for pollutants with more global and longer-term effects, and higher abatement costs (e.g., $\mathrm{CO}_{2}$ ). In many studies where an EKC is apparently uncovered the levels of real per capita income, above which pollution begins to decline, are exceedingly high relative to actual current levels. In addition, the clarity of many EKC results diminishes once covariates other than real per capita income are taken into consideration. A further issue that has, to the best of our knowledge, been taken into account in the empirical EKC literature only by Egli (2001), is the fact that many of the studies have been based on time-series data that are undoubtedly non-stationary. As noted above, the research reported by Jacobsen and Giles (1998) clearly indicates the importance of taking account of unit roots and cointegration in the data when estimating Kuznets' curves.

Indeed, the more recent empirical evidence is not especially favourable towards 'literal' EKC relationships. Harbargh et al. (2000) re-examine the earlier World Bank and Grossman-Krueger data and find that the evidence that the latter authors presented in favour of EKC's for $\mathrm{SO}_{2}$, 
smoke and total suspended particulates are actually very sensitive to the sample period and to controlling for other factors. On balance, they reject the simple EKC for these emissions. Among the more positive recent results are those of Hilton and Levinson (1998), who examine emissions of lead as a result of gasoline consumption in 48 countries over a 20 -year period. They consider various functional forms and find an EKC with a statistically significant peak at a real (1990) per capita income of around US\$11,000, when only post-1983 data are used. The many other recent contributions to this literature include three that are of particular interest to us here - those of Roca et al. (2001) and Egli (2001), and Utt et al. (2001). The first two of these studies appear to be the only ones to date that attempt to estimate an EKC explicitly for methane. Roca et al. consider Spanish data for the emissions of six atmospheric pollutants $-\mathrm{CO}_{2}$ (for the period 1972 to 1996) and $\mathrm{SO}_{2}, \mathrm{~N}_{2} \mathrm{O}, \mathrm{CH}_{4}, \mathrm{NO}_{\mathrm{x}}$ and non-methanic volatile organic compounds (NMVOC) for the period 1980 to 1996 . With the exception of $\mathrm{SO}_{2}$ they fail to find satisfactory econometric relationships to support EKC's for any of these pollutants. Using German time-series data for the period 1966 to 1998, Egli considers emissions of eight pollutants - $\mathrm{NO}_{\mathrm{x}}, \mathrm{NH}_{3}, \mathrm{SO}_{2}, \mathrm{CH}_{4}, \mathrm{CO}$, $\mathrm{CO}_{2}$, NMVOC and SPM. He uncovers standard EKC relationships for the first two of these. When the non-stationarity of the data are taken into account and a modified error-correction model is estimated, there is mild evidence to support a long-run EKC for methane emissions. Utt et al. estimate an EKC for total per capita equivalent- $\mathrm{CO}_{2}$ for the U.S.A., using data for 1922 to 1996. Not only is the length of their sample much greater than is usual in such studies, and more in keeping with our own, but their calculation of equivalent- $\mathrm{CO}_{2}$ includes an allowance $\mathrm{CH}_{4}$ and other GHG's. ${ }^{11}$ They use a quartic polynomial to estimate an EKC that has local maxima at US $\$ 8,000$ and US\$28,000, and a local minimum at about US\$20,000. ${ }^{12}$

\section{Data Issues}

One of the distinguishing features of this study is its use of a very long-term set of data. ${ }^{13}$ Moreover, we are fortunate to have access to data of very high quality. The data for enteric methane emissions have been constructed by multiplying animal numbers, as reported by the New Zealand Ministry of Agriculture and Forestry (2003), by the methane emission rates used by Clarke (1999) in the preparation of that country's national GHG inventory. ${ }^{14}$ These rates are given in Table 1 for each type of ruminant farmed in New Zealand, with low (L) and high (H) estimates given for 1990 and $1999 .{ }^{15}$ The four emission rate estimates give rise to four series for total enteric $\mathrm{CH}_{4}$, which we denote $\mathrm{CH}_{4} 90 \mathrm{~L}, \mathrm{CH}_{4} 90 \mathrm{H}, \mathrm{CH}_{4} 99 \mathrm{~L}$ and $\mathrm{CH}_{4} 99 \mathrm{H}$ in Figure 1, for the period 1895 to $1996 .^{16}$ This allows us to check the sensitivity of our results to assumptions about 
methane emission rates per animal. The estimates of total enteric methane were then divided by 1,000 and by official population estimates to yield data expressed in tonnes per capita for the purposes of our regression analysis.

Our real per capita GDP index (base $=100$ in 1990) is plotted in Figure 2 over the same time period. This index was constructed by splicing the series for the period 1866 to 1933 recently developed by Greasley and Oxley (2000), with Maddison's (1995) data for New Zealand for the period 1933 to 1994). The index was then extended to 1996 by using real GDP data from Statistics New Zealand (1998) and the associated population figures. The plots in Figures 1 and 2 strongly suggest that our data may be non-stationary, and we deal with this issue in detail in section 5 below.

Table 1

Estimated Enteric $\mathrm{CH}_{4}$ Emission Rates

For New Zealand Farmed Ruminants

(Kg./Animal per year)

\begin{tabular}{lllll}
\hline & \multicolumn{2}{c}{$\mathbf{1 9 9 9}$} & \multicolumn{2}{c}{$\mathbf{1 9 9 0}$} \\
& High* & Low** & High* & Low** \\
\hline Sheep & 17.1 & 15.39 & 15.1 & 13.59 \\
Dairy Cows & 79.0 & 75.05 & 76.8 & 72.96 \\
Beef Cattle & 70.8 & 67.26 & 67.5 & 64.125 \\
Deer & 22.6 & 21.47 & 22.6 & 21.47 \\
Goats & 10.5 & 9.975 & 10.5 & 9.975 \\
\hline
\end{tabular}

*See Clark (2001), Table 1. These are based on an updated version of Baldwin's estimation algorithm (Donovan and Baldwin, 1999).

** See Clark (2001). These are derived using the reduction factors claimed to be needed as a result of overstatements arising from Baldwin's estimation algorithm. 
Figure 1

Enteric Methane Emissions (1895 - 1996)

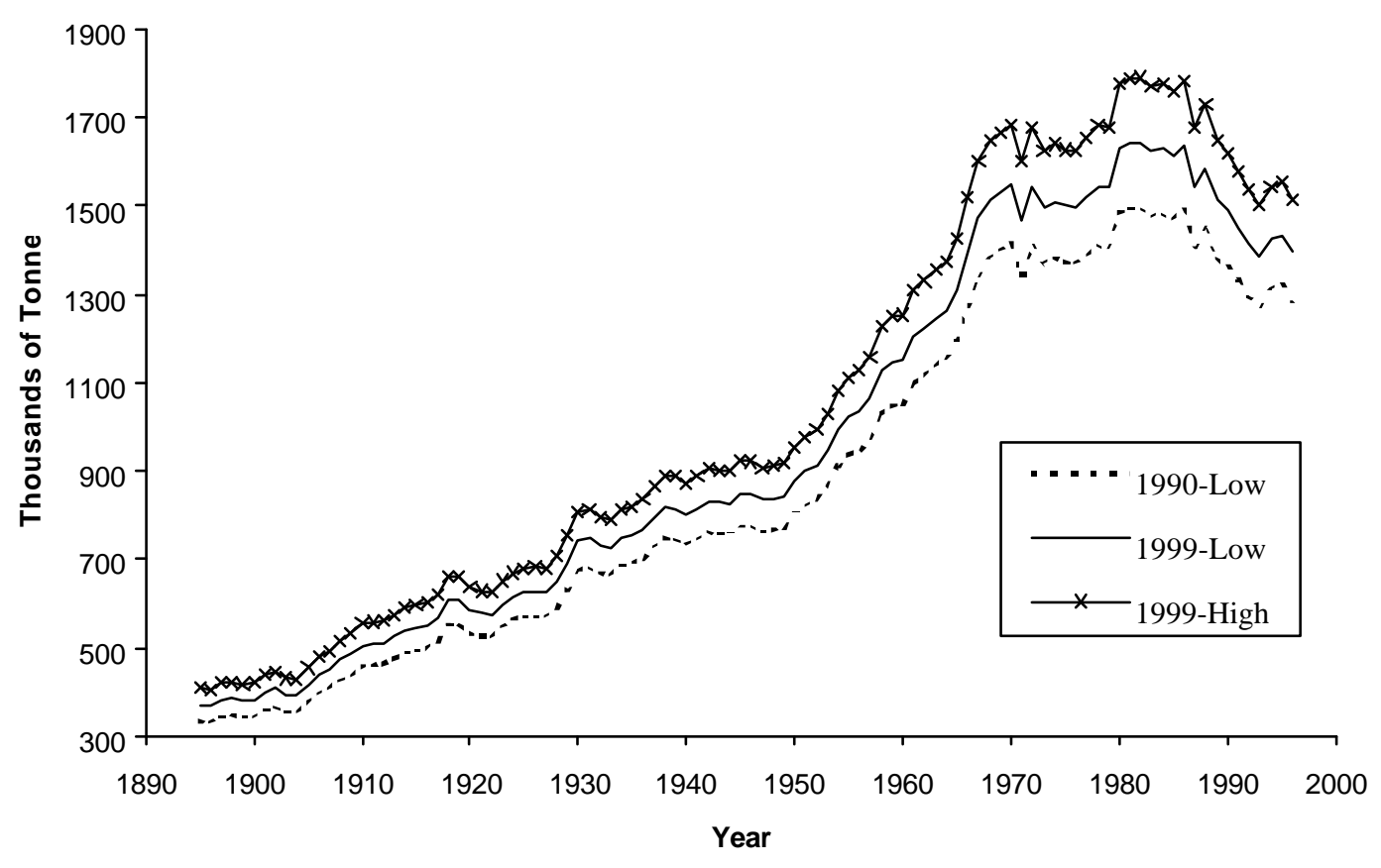

Figure 2

Real Per Capita GDP Index $(\mathbf{1 9 9 0}=\mathbf{1 0 0})$

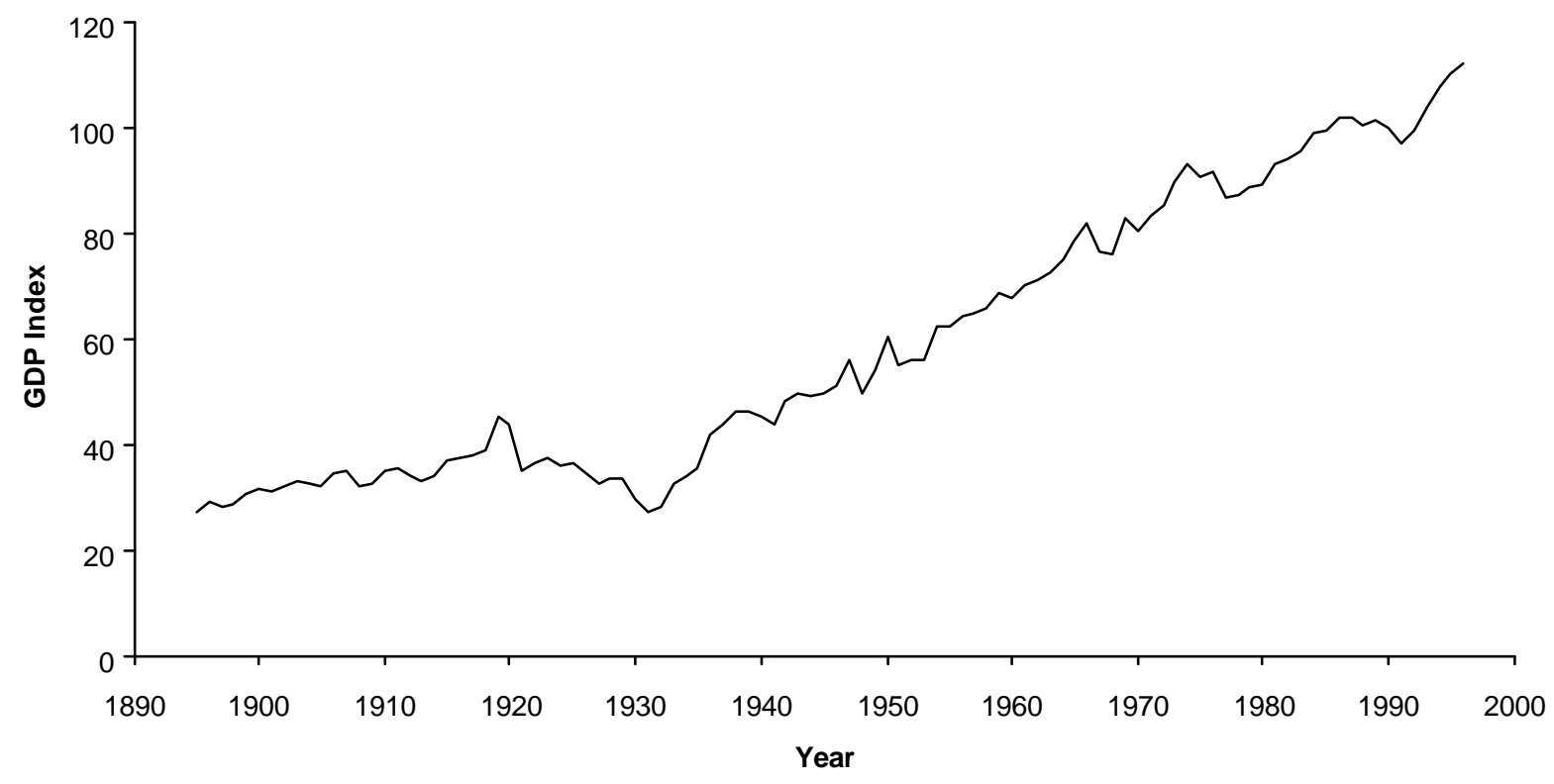




\section{Modelling and Estimation Strategies}

Typically, attempts to establish the existence of an EKC have been based on regression models in which the level of the pollutant in question is 'explained' in terms of real income, or some simple polynomial of the latter. These models sometimes include additional regressors to control for other relevant factors, and some of them allow for dynamic effects through the inclusion of a lagged value of he dependent variable. EKC's have been estimated from cross-country data, time-series data, or 'pooled' data Regrettably, many of the studies that use the latter two types of data do not allow for the possibility that these data are non-stationary, and this brings the relevance of their results into question in view of the fact that some are undoubtedly based on 'spurious regressions'. ${ }^{17}$ Among the few EKC studies that attempt to take at least some account of unit roots in the data are those of Stern and Common (2001), Egli (2001), Roca et al. (2001), but none of these test for multivariate cointegration.

Almost without exception, the models in these studies are parametric, and the use of an explicit functional form places crucial constraints on the results that can be obtained. As an obvious example of this, if the regressors include GDP and its squared value (but no higher powers of GDP), then the partial relationship between the amount of pollution and GDP simply has to be ' $\mathrm{U}$ shaped' or 'inverted-U shaped', depending on the signs of the estimated coefficients. It cannot have more than one turning point. ${ }^{18}$ In practice, estimated EKC's have been found to be quite sensitive to the type of pollutant under study, to changes in the type and sample of data used, and to the specification of the model's functional form.

One obvious way to deal with this last type of sensitivity is to avoid placing any parametric constraints on the model at all, and to use nonparametric kernel regression. Somewhat surprisingly, it seems that this option has been pursued in only one previous EKC study. Taskin ad Zaim (2000) compare nonparametric regression with simple parametric polynomial specifications in the case of $\mathrm{CO}_{2}$ emissions for 52 countries over the period 1975 to 1990. Their nonparametric results suggest a relationship that is broadly similar in appearance to a cubic one. An alternative to nonparametric regression is to use splines (piecewise continuous, usually simple polynomial, functions). One application of this idea in the context of the EKC is the study by Schmalensee et al. (1998) who find a clear 'inverted-U' $\mathrm{EKC}$ for $\mathrm{CO}_{2}$ when simple spline analysis is used in conjunction with nationatlevel panel data for the period 1950 to 1990. Similarly, Hilton and Levinson (1998) include some basic (linear) spline regression analysis in 
their study and they also find a significant EKC, in their case for lead arising from the use of gasoline.

In the present study not only do we consider the usual polynomial specifications that are common in the empirical EKC (and 'regular' Kuznet's curve) literature, and nonparametric kernel regression, but we also use a new and very flexible regression modelling procedure that has been developed by Giles and Draeseke (2003). ${ }^{19}$ This 'fuzzy regression' approach involves using fuzzy clustering techniques (from the pattern recognition literature) to partition the data into subsamples over which separate parametric regressions are then fitted. A weighted average of the sub-sample results is then formed, using the 'degrees of membership' for each data point and each cluster as weights. As these weights vary continuously from one data point to another, we are able to capture complex non-linearities very successfully. ${ }^{20}$ In a range of different modelling applications, Giles and Draeseke (2003) demonstrate that this methodology out-performs nonparametric kernel regression, and standard parametric regression, often quite dramatically. As this fuzzy regression framework is not yet widely known, we present some details here. ${ }^{21}$

Fuzzy set theory originated with Zadeh (1965). ${ }^{22}$ In conventional set theory, items either belong to some particular set or they do not. That is, the 'degree of membership' of an element with respect to any particular set is either unity or zero. The boundaries of the sets are 'sharp', or 'crisp'. In the case of fuzzy sets, the degree of membership may be any value between zero and unity, and every item is associated with all of the sets. Usually this association will involve different degrees of membership for each item (data point) with each of the fuzzy sets.

In order to implement our fuzzy regression analysis we use the so-called 'fuzzy c-means' (FCM) algorithm that is widely used in the pattern recognition literature, together with some basic concepts from fuzzy logic. ${ }^{23}$ The FCM algorithm, which is described in the appendix, enables us to partition the data into a fixed number of clusters, based on the values of the regressor(s). These clusters have 'fuzzy' boundaries, in the sense that each data value belongs to every cluster to some degree or other. The FCM algorithm determines the cluster mid-points, the associated membership functions and degrees of membership for all of the data-points. Separate regressions are fitted over each of he clusters, and the degrees of membership provide the basis for combining the separate results into one prediction for the conditional mean of the dependent variable in the model. 


\section{A Long-Run EKC for Enteric $\mathrm{CH}_{4}$ in New Zealand}

The time-series data that we use in our modeling have first been tested for stationarity using both the 'augmented' Dickey-Fuller (ADF) tests and the tests proposed by Kwiatovsky et al. (KPSS) (1992). For the ADF 't-tests' (Dickey and Fuller, 1979, 1981; Dickey and Said, 1981) the null hypothesis is that the series has a unit root and the alternative hypothesis is that it is stationary. The null and alternative hypotheses are reversed for the KPSS tests. In the case of the ADF tests we have considered the usual three cases for the Dickey-Fuller regressions: including a drift (constant term) and a linear trend (DT); including a drift but no trend (DNT); and no drift or trend (NDNT). The number of augmentation terms for the ADF tests was determined by using the Schwarz information criterion (Schwarz, 1978). In the case of the KPSS tests we consider the usual two variants of the null hypothesis, namely level stationarity and trend stationarity. Our results, obtained with the EViews (2002) econometrics package and based on the full time-period, 1895 to 1996, appear in part (a) of Table 2 It is well known that these unit root tests lack power in finite samples, so in practice it is often wise to adopt a relatively conservative significance level such as $10 \%$. Using the exact finite-sample critical values for the ADF test given by MacKinnon (1991), and those for the KPSS test given by Hornok and Larsson (2000), we find that all of our series have a unit root (i.e., they are $\mathrm{I}(1)) .^{24}$

Given the close similarity between the characteristics of each of the four enteric methane series, as evidenced in Figure 1 and Table 1, all of the following discussion and the results that are presented below are based only $\mathrm{CH}_{4} 90 \mathrm{~L}$. This provides the most conservative estimates of methane emissions, and it uses animal emission rate estimates that are based on scientific data as far from the end-point(s) of our sample as are available. ${ }^{25}$

In part (b) of Table 2 we present the results of testing for multivariate cointegration between $\mathrm{CH}_{4}$ 90L, GDP, GDP ${ }^{2}$ and GDP ${ }^{3}$, using Johansen's $(1988,1995)$ likelihood-based procedures. As data exhibit a trend, following the suggestion of Franses (2001) we include a drift and trend in the cointegrating equation, and a drift but no trend in the VAR models when applying Johansen's procedure. This corresponds to 'case 4 ' in the EViews (2002) econometrics package. The lag lengths for the VAR models were determined using the Schwarz information criterion and Akaike's (1973) information criterion. As can be seen from Table 2, the results of both the trace tests and the max.-eigenvalue tests clearly indicate the presence of cointegration (with at most one or two cointegrating vectors (CV's)) between the variables in question. This is particularly 
important as it determines the appropriate way to estimate the EKC. In fact, we have two legitimate choices - we can either model a short-run dynamic relationship by estimating an 'error-correction model'; or we can fit the model in terms of the levels (not the differences) of the data and determine the long-run equilibrating relationship. It is the latter that is relevant in the case of an EKC. Moreover, OLS estimation will yield 'super-consistent' estimates of the model's parameters. $^{26}$

Table 3 presents the results obtained when we estimate some basic parametric EKC's for enteric methane emission in New Zealand, using OLS estimation. These are based on both quadratic and cubic specifications, explaining per capita methane in terms of real per capita GDP. Several summary statistics and diagnostic test results are included in Table 3. The usual (asymptotic) Lagrange multiplier test statistic for serial independence of the errors (against the alternative hypothesis of a simple AR(i) or MA(i) process) is denoted LMi (i = 1, 2). The Jarque and Bera (1980) test for normality of the errors is denoted JB; and FREi $(i=1,2,3)$ denotes the 'FRESET' test for mis-specification of functional form and/or omitted regressors proposed by DeBenedictis and Giles $(1998,1999){ }^{27}$

The significance of the estimated coefficients is quite apparent, and the t-value associated with $\mathrm{GDP}^{3}$ confirms that a cubic specification is preferred over the more restrictive quadratic relationship. However, in the two static models the tests for serial independence, and several of the FRESET test results, suggest that the formulation of the model requires further consideration. Estimating simple dynamic models that include a lagged value of the dependent variable yields more robust results. The estimated static and (long-run) dynamic relationships are shown in Figures 3(a) and (b) respectively. ${ }^{28}$ We see that classic 'inverted U' curves emerge when a quadratic relationship is fitted, with the location of the maximum essentially unaffected by allowing for dynamics in the specification of the EKC. The (preferred) cubic EKC's attain a maximum at a higher level of GDP than do the quadratic ones, but again the general conclusions are insensitive to the dynamics of the model. Based on the cubic specification, these rather restrictive and conventional parametric regression results suggest that the $\mathrm{EKC}$ for enteric methane emissions in New Zealand peaked at a GDP level of approximately NZ $\$ 11,000$ (US\$8,777) per capita, in real 1990 dollar terms. 
Table 2

Tests for Data Stationarity \& Cointegration

(1895 - 1996; $T=102)$

(a) Unit Root Tests

\begin{tabular}{llllll} 
& \multicolumn{3}{c}{ ADF* } & \multicolumn{2}{c}{ KPSS } \\
& NDNT & DNT & DT & $\begin{array}{l}\text { Level } \\
\text { Stationary }\end{array}$ & $\begin{array}{l}\text { Trend } \\
\text { Stationary }\end{array}$ \\
& & & & & \\
& & & & & \\
$\mathrm{GDP}$ & $3.104(0)$ & $0.746(0)$ & $-1.817(0)$ & $1.177^{+}$ & $0.271^{+}$ \\
$\mathrm{CH}_{4} 90 \mathrm{~L}$ & $-0.897(0)$ & $-1.704(1)$ & $-0.941(0)$ & 0.136 & $0.129^{\#}$ \\
$\mathrm{CH}_{4} 90 \mathrm{H}$ & $-0.947(0)$ & $-1.697(1)$ & $-1.584(1)$ & 0.125 & $0.123^{\#}$ \\
$\mathrm{CH}_{4} 99 \mathrm{~L}$ & $-0.979(0)$ & $-1.687(1)$ & $-1.601(1)$ & 0.116 & $0.119^{\#}$ \\
$\mathrm{CH}_{4} 99 \mathrm{H}$ & $-0.947(0)$ & $-1.697(1)$ & $-1.584(1)$ & 0.125 & $0.123^{\#}$
\end{tabular}

(b) Johansen Cointegration Tests**

\begin{tabular}{lllll} 
& \multicolumn{2}{c}{ Quadratic } & \multicolumn{2}{c}{ Cubic } \\
Null Hypothesis & Trace & Max-Eigenvalue & Trace & Max-Eigenvalue \\
\hline No C.V.'s & $49.165^{+}$ & $34.398^{+}$ & $94.384^{+}$ & $39.345^{+}$ \\
At Most 1 C.V. & 17.767 & 9.451 & $55.038^{+}$ & $30.754^{+}$ \\
At Most 2 C.V.s & 5.317 & 5.317 & 24.285 & 18.287 \\
At Most 3 C.V.'s & n.a. & n.a. & 5.997 & 5.997 \\
\hline
\end{tabular}

* Number of augmentation terms (lags) given in parentheses.

** Number of lags in the VAR models is 7.

$+\quad$ Significant at the $1 \%$ level.

\# $\quad$ Significant at the $10 \%$ level. 
Table 3

Parametric Regression Results ${ }^{*++}$

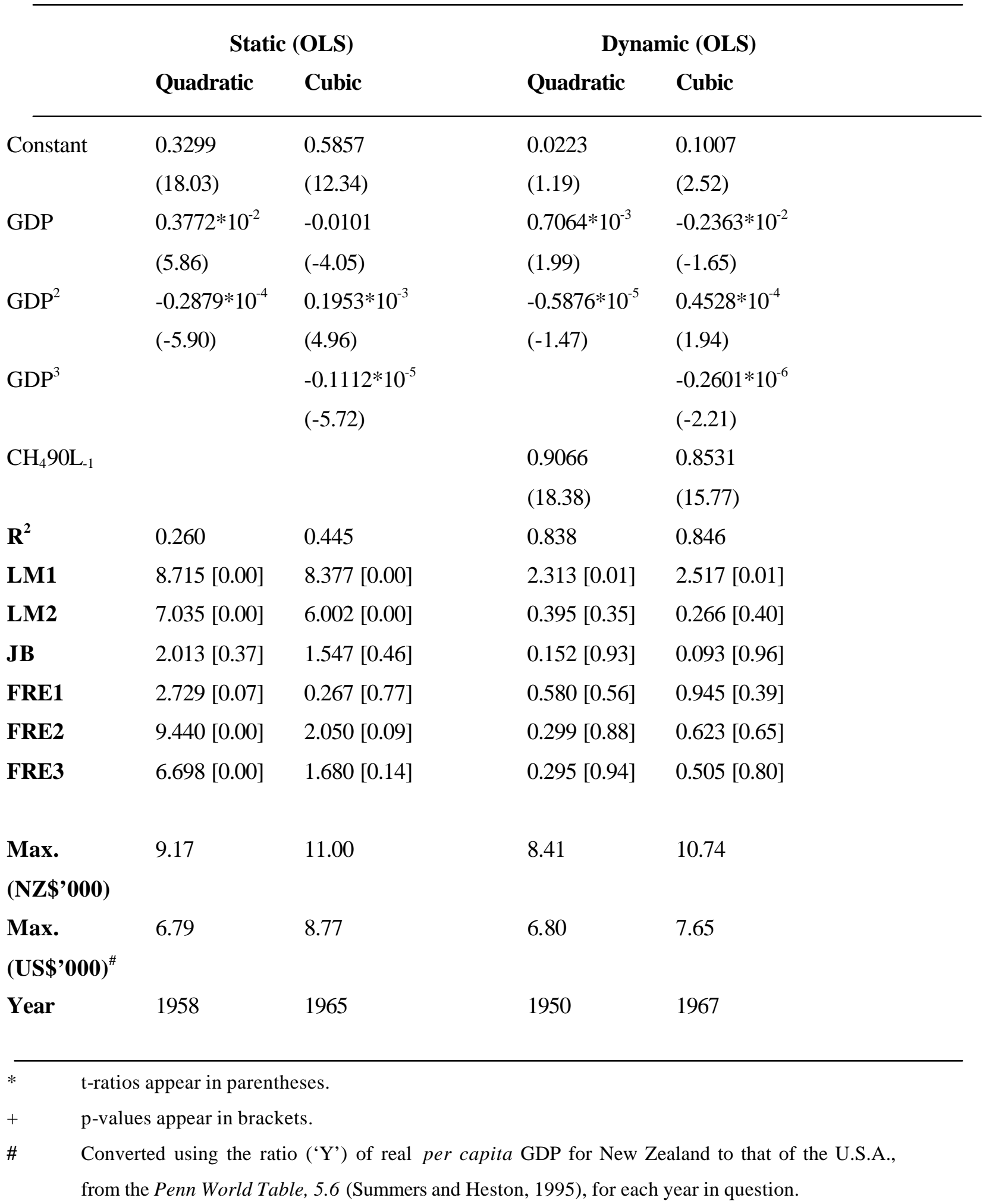


Figure 3(a)
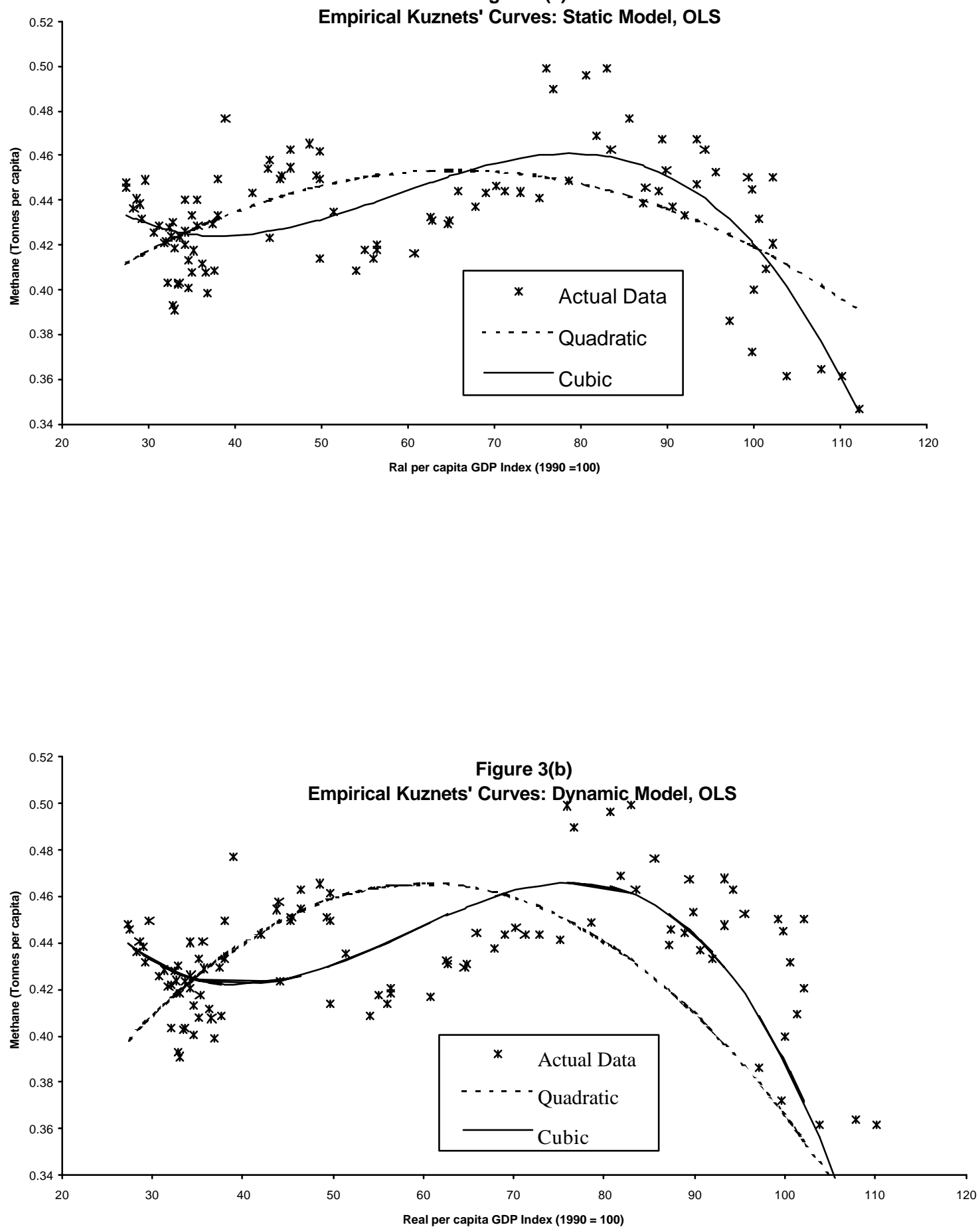
To avoid the unnecessary restrictiveness of these polynomial specifications we have also estimated our EKC for methane using both nonparametric kernel regression, and more particularly the fuzzy regression procedure outlined in section 4 and in the Appendix. In the former case we used a normal kernel with the optimal bandwidth chosen by the default method in the SHAZAM (2001) econometrics package, and the fitted model is depicted in Figure 4. In the fuzzy regression analysis we explored the use of two, three and four fuzzy clusters. The results based on $c=3$ and $c=4$ were very similar to each other, so only those based on $c=2$ and $c=3$ appear in Figure 4. Figures 5(a) and 5(b) show the 'membership functions' associated with the data points in the fuzzy clustering analysis. This is the first application of fuzzy regression in the context of EKC's. ${ }^{29}$ Some features of the 'within-cluster' regression estimates are given in Table 4(a). It is important to note that because the GDP data are not strictly monotonic increasing, it is not the case that the first cluster regression when $c=2$ is based on the first (temporal) 61 data values, for example. The locations of the (global) maxima of the estimated EKC's are also shown in Table 4(a), in terms of real (1990) per capita New Zealand and U.S. dollars, and the year of attainment.

In part (b) of Table 4 we see that the fuzzy regression analysis, based on three fuzzy clusters, outperforms the other estimation techniques on the basis of both root mean squared error and mean absolute error. Although there is virtually no difference between the fits of the fuzzy $(c=3)$ and nonparametric kernel EKC's, or between the real per capita GDP levels at which their global maxima are attained, the fuzzy regression based on three clusters reveals a 'double-hump' relationship that does not emerge with any of the other estimators. ${ }^{30}$ Interestingly, this is consistent with the theoretical EKC model proposed by Bousquet \& Favard (2000), and discussed in section 2 above.

\section{Further Considerations}

As was noted in section 1, New Zealand is heavily dependent on agriculture and forestry for its revenue from exports, and in $199944.1 \%$ of that revenues was 'pastoral based' and hence dependent on the ruminants that are responsible for almost all of the country's methane emissions. New Zealand is also an extremely 'open' economy. Using the ratio of total trade (exports plus imports) to GDP as the (usual) measure, in percentage terms the openness of the New Zealand economy peaked at 74\% in 1919 (reflecting the resumption of trade after World 
Figure 4

Empirical Kuznets' Curves: Fuzzy \& Nonparametric Estimation

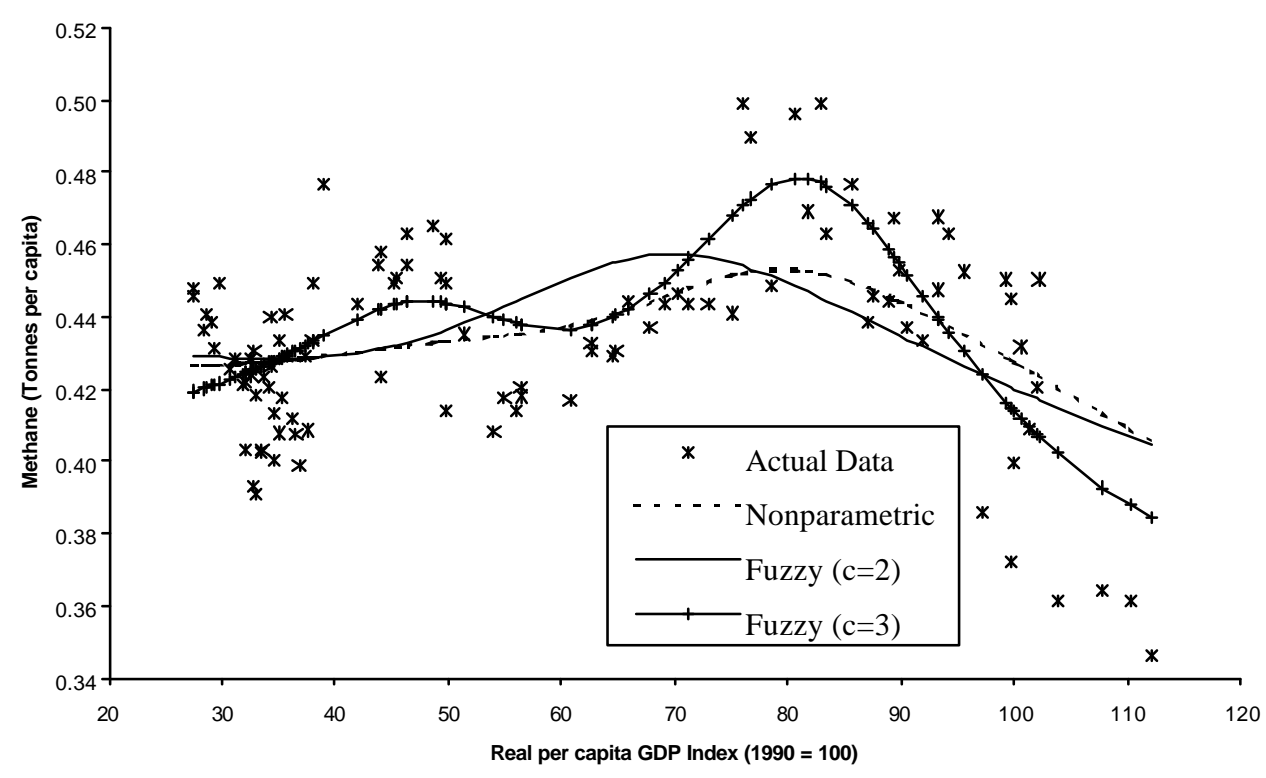


War I) and at $71 \%$ in 1952 (reflecting the Korean War Boom). ${ }^{31}$ The median openness rate over the period 1918 to 1998 was 48\%, and the figures for 1918, 1958 and 1998 were 58\%, 48\% and $46 \%$ respectively. By way of comparison, the corresponding figures for the U.S.A. in these three years were only $12 \%, 7 \%$ and $18 \%$; for the United Kingdom they were 38\%, 39\% and $41 \%$; and for Australia they were $39 \%, 31 \%$ and $34 \%$. For Canada, the openness figure ranged from $33 \%$ in 1926 to $22 \%$ and $47 \%$ in 1958 and 1998 respectively. ${ }^{32}$ The New Zealand economy is heavily reliant on trade, and in particular it is (and always has been) heavily dependent on exports of such 'pastoralbased' products as wool, lamb and mutton, live sheep, butter and cheese, skimmed milk powder, and more recently venison and deer antler 'velvet'. ${ }^{33}$ Given the intimate connection between the production of these exports and the generation of enteric $\mathrm{CH}_{4}$ emissions, one obvious question that arises is whether or not the associated EKC is at least partially determined by the (relative) price of exports. Given the pivotal role of sheep in New Zealand, both in terms of exports and in terms of methane emissions, wool prices may be of special relevance. This is reinforced by New Zealand's continued standing as a top international producer of this product still the third largest in the world in 2000/2001. ${ }^{34}$

We have experimented with various versions of our EKC models by including values of the wool price index (deflated either by the consumer price index, or by the export price index for New Zealand). To take account of the time delay likely to be associated with reductions (increases) in sheep stocks as farmers respond to rises (falls) in the relative price of wool, we also considered lagged values of the deflated wool price index in the models. However, we were unable to find any specifications with a significant and positive price effect. Indeed, in most cases the wool price variable had an insignificant negative coefficient, which is not surprising in view of the negative sample correlations between $\mathrm{CH}_{4} 90 \mathrm{~L}$ and the two real wool price series. ${ }^{35}$ It seems clear that New Zealand's methane emission problems are not responsive to the associated international prices.

As can be seen in Figure 2, real per capita output has followed a strong upward trend in New Zealand since the Great Depression, and Giles et al. (1992) have established the existence of significant (Granger) causality from exports of certain goods and services to real GDP in that country. In the context of our EKC results, this suggests that it would be a mistake for New Zealand's policy-makers to look to livestock (and hence exports) reduction as a means of achieving their Kyoto Protocol commitments with respect to methane emissions. Moreover, were 
they to do so (such as through a reinstatement of sheep retention subsidies), the effects of the associated trade diversion could result in net increase in worldwide emissions of enteric $\mathrm{CH}_{4}$. For example, assuming no change in the international demand for wool and sheep meats, but with the New Zealand supply diminished, prices for these products would rise on international markets and other countries would increase their sheep stocks. The countries most likely to respond in this way are ones (such as China, Argentina, Uruguay and South Africa) with lower real per capita GDP than New Zealand. ${ }^{36}$ To the extent that our EKC results for methane apply internationally, this would lead to a net increase in enteric methane emissions. Relatively high income countries have a comparative advantage in finding technologic al solutions for pollution problems such as methane emissions, and from a global perspective policy-makers in New Zealand are correct in pursuing their current scientific efforts to reduce $\mathrm{CH}_{4}$ emission rates per animal.

The agricultural research base in that country is exceptionally strong, and recently there has been intensive research into methods of measuring and reducing methane emission rates among ruminants (especially sheep and cattle). On-the-farm measurements of enteric methane emissions in New Zealand date from 1996, with the development of a micro-meteorological method of measuring net methane emissions from flocks of free-ranging sheep, taking into account the oxidation or consumption of methane by soil bacteria. ${ }^{37}$ Dietary intake is an important determinant of enteric $\mathrm{CH}_{4}$ emissions. For example, Ulyatt et al. (2002) report on the extent to which these emissions can be reduced by modifying the type of pasture to include sub-tropical kikuyu grass (Pennisetum clandestinum). Other research indicates that emission rates fall as the condensed tannin content of the food is increased. Such research is not limited to New Zealand. For example, experiments at the Institut National de la Recherche Agronomique in France have involved lambs, born by caesarian section, being reared in a sterile environment. The animals have been inoculated with all the usual bacteria from the rumen of ordinary sheep, except for the methane-producing bacteria. The results to date indicate that the elimination of the bacteria does not affect the growth or productive capabilities of the sheep. Related research in Australia has resulted in experimental trials of a vaccine that discourages Methanogenic archae, the organisms which inhabit the animal's digestive system and produce methane by breaking down feed. 
Table 4

Fuzzy and Nonparametric Regression Results

(a) Fuzzy Regression Sub-Model Results

\begin{tabular}{|c|c|c|c|c|c|}
\hline c & $\begin{array}{l}\text { Fuzzy } \\
\text { Cluster }\end{array}$ & $\mathbf{T}$ & $\begin{array}{l}\text { Cluster } \\
\text { Centre }\end{array}$ & $\begin{array}{l}\text { Slope } \\
\text { (t-value) }\end{array}$ & $\begin{array}{l}\text { Intercept } \\
\text { (t-value) }\end{array}$ \\
\hline \multirow[t]{2}{*}{2} & 1 & 61 & 39.032 & $\begin{array}{l}0.2767 * 10^{-3} \\
(1.06)\end{array}$ & $\begin{array}{l}0.4182 \\
(39.25)\end{array}$ \\
\hline & 2 & 41 & 89.826 & $\begin{array}{l}-0.1529 * 10^{-2} \\
(-4.07)\end{array}$ & $\begin{array}{l}0.5722 \\
(17.15)\end{array}$ \\
\hline \multirow[t]{3}{*}{3} & 1 & 49 & 35.291 & $\begin{array}{l}0.1291 * 10^{-2} \\
(2.23)\end{array}$ & $\begin{array}{l}0.4702 \\
(22.31)\end{array}$ \\
\hline & 2 & 24 & 64.117 & $\begin{array}{l}0.1689 * 10^{-2} \\
(3.33)\end{array}$ & $\begin{array}{l}0.4147 \\
(12.79)\end{array}$ \\
\hline & 3 & 29 & 95.786 & $\begin{array}{l}-0.4938 * 10^{-2} \\
(-7.41)\end{array}$ & $\begin{array}{l}0.9839 \\
(15.49)\end{array}$ \\
\hline
\end{tabular}

(b) Comparative Model Performances*

\begin{tabular}{llllll}
\hline & \multicolumn{2}{c}{ OLS } & & \multicolumn{3}{c}{ Fuzzy } & Nonparametric \\
& Quadratic & Cubic & $\mathbf{c = 2}$ & $\mathbf{c = 3}$ & \\
& & & & & \\
RMSE & 0.0565 & 0.0517 & 0.0244 & 0.0201 & 0.0228 \\
MAE & 0.0321 & 0.0254 & 0.0201 & 0.0168 & 0.0179 \\
Max. & 8.41 & 10.74 & 9.74 & 11.28 & 11.28 \\
(NZ\$'000) & & & & & \\
Max. & 6.80 & 7.65 & 7.70 & 8.14 & 8.14 \\
$($ US\$'000)* & & & & & \\
Year & 1950 & 1967 & $1959-1961$ & 1970 & 1970 \\
\hline
\end{tabular}

* Converted using the ratio ('Y') of real per capita GDP for New Zealand to that of the U.S.A., from the Penn World Table, 5.6 (Summers and Heston, 1995), for each year in question. 
Figure 5(a)

Fuzzy Clustering Membership Functions (c = 2)

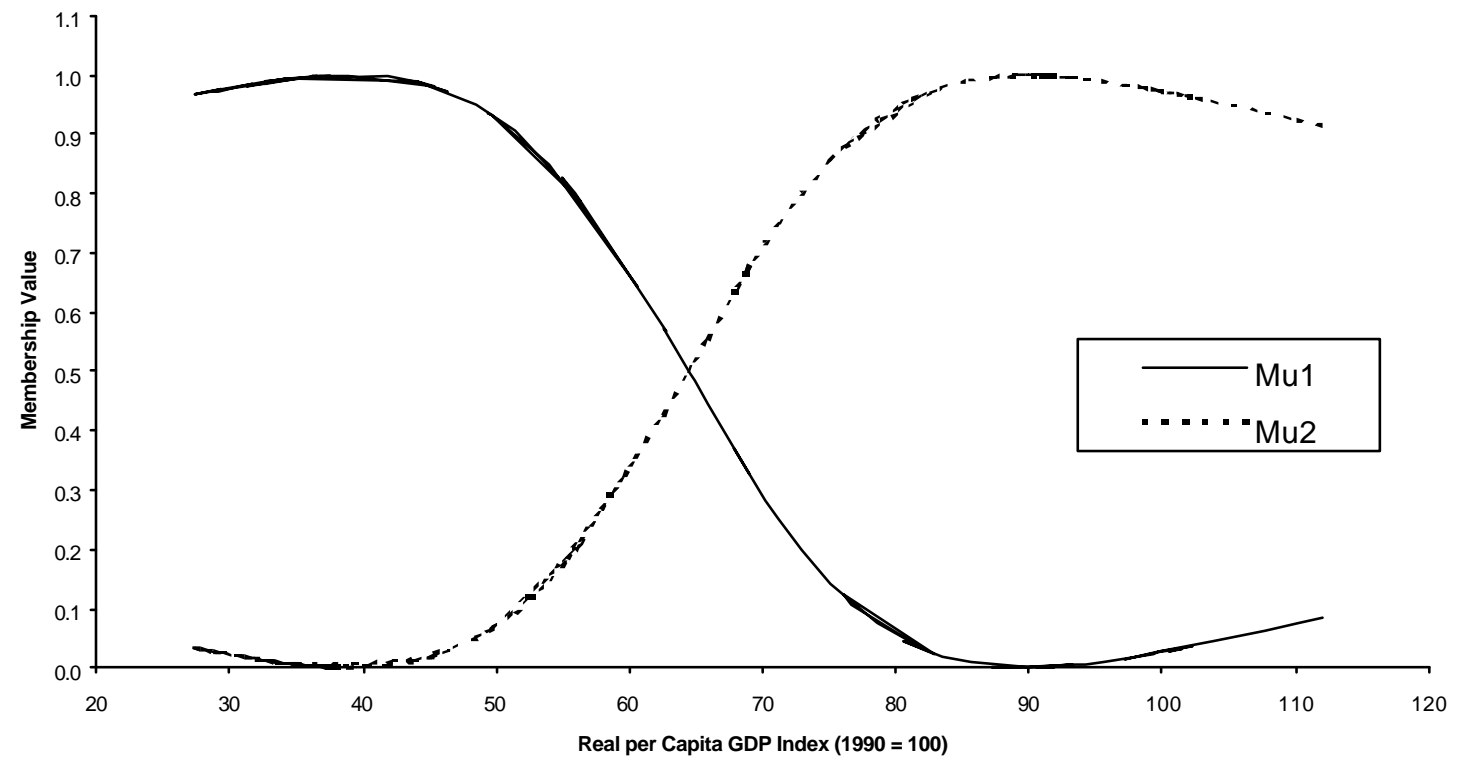

Figure 5(b)

Fuzzy Clustering Membership Functions (c = 3)

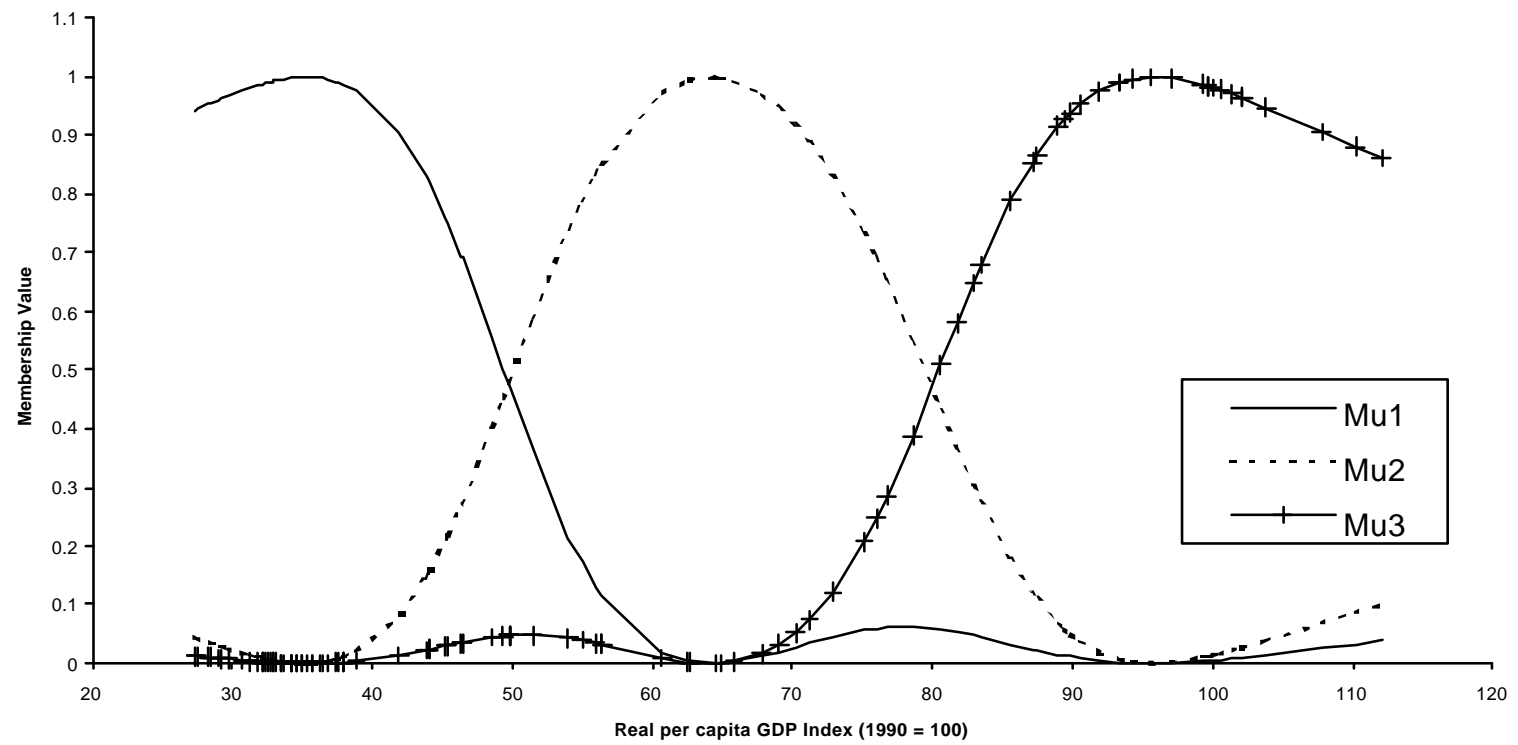




\section{Conclusions}

In this paper we have studied the relationship between enteric methane emissions and real per capita GDP in New Zealand, using traditional and new techniques to estimate an environmental Kuznets' curve for this GHG. Among the noteworthy features of this research are: our use of data spanning more than a century; the application of new 'fuzzy regression' techniques to unearth the nonlinear characteristics of the relationship in a flexible manner; and the focus on a little-studied GHG that is of primary concern to this major wool-producing country in meeting its obligations as a signatory to the Kyoto Protocol.

It is not the purpose of this paper to offer a theoretical basis for the relationship between methane emissions and income, but our empirical results indicate that there is an environmental Kuznets' curve for $\mathrm{CH}_{4}$ in New Zealand. Our preferred results, based on 'fuzzy regression' methods suggest that the curve has a 'double-hump', with a maximum at a GDP level of just over US\$8,000 per capita, in real 1990 dollar terms. This general shape for the EKC is consistent with the results of Taskin and Zaim (2000) and Dijkgraaf and Vollebergh (2001) for $\mathrm{CO}_{2}$, and is suggested by the theoretical model of Bousquet \& Favard (2000). Our nonparametric kernel regression results suggests a curve with a single maximum at the same level of income, while levels of the order of US\$7,000-US\$7,500 are implied by our standard quadratic and cubic regressions. These turning point levels are very consistent with the results of other studies relating to various GHG emissions internationally, as is evidenced by the discussions in Grossman and Krueger (1995) and Hilton and Levinson (1998).

Lowering enteric methane emissions by reducing livestock numbers is not a viable option for New Zealand, given its dependence on pastoratbased exports, and the established causality between its exports and GDP. Our positive findings with respect to an environmental Kuznets' curve for $\mathrm{CH}_{4}$ suggest that this economic 'fact of life' may be fortuitous - it seems that any significant reduction in real GDP from its recent levels would lead to an increase in the emissions of this GHG. With its relatively high per capita GDP, New Zealand has always invested heavily (and successfully) in agricultural research. A number of positive recent scientific developments suggest that methane emissions in that country will be curtailed (and livestock productivity will be increased) through vaccinations and dietary changes. Our findings with respect to an environmental Kuznets' curve suggest that there will also be a reinforcing effect as enhanced exports have a positive impact on real output. 


\section{Appendix \\ Fuzzy Econometric Modelling}

\section{The Fuzzy c-Means Algorithm}

The FCM algorithm provides a method for dividing up the ' $n$ ' data-points into ' $c$ ' fuzzy clusters (where $c<n$ ), while also locating the centres of these clusters. The metric that forms the basis for the usual FCM algorithm is usually 'squared error distance', though the use of an 'absolute error distance' can be used to deal with outliers in the data. (See Stroomer and Giles, 2003). The mathematical details of the algorithm are as follows. Let $\boldsymbol{x}_{k}$ be the $k^{\text {th }}$ (possibly vector) data-point $(k=1,2, \ldots ., n)$. Let $\mathbf{v}_{\mathrm{i}}$ be the centre of the $i^{\text {th }}$ (fuzzy) cluster $(i=1,2, \ldots ., c)$. Let $d_{i k}=\left\|\boldsymbol{x}_{k}-\boldsymbol{v}_{i}\right\|$ be the distance between $\boldsymbol{x}_{k}$ and $\boldsymbol{v}_{i}$, and let $u_{i k}$ be the 'degree of membership' of data-point ' $k$ ' in cluster ' $i$ ', where :

$$
\sum_{i=1}^{c}\left(u_{i k}\right)=1
$$

The objective is to partition the data-points into the ' $c$ ' clusters, locate the cluster centers, and also determine the associated 'degrees of membership', so as to minimize the functional

$$
J(U, v)=\sum_{i=1}^{c} \sum_{k=1}^{n}\left(u_{i k}\right)^{m}\left(d_{i k}\right)^{2}
$$

While there is no explicit basis for choosing the value of the parameter ' $m$ ', which must satisfy 1 $<m<\infty$, with $m=1$ corresponding to 'hard clustering'. In practice $m=2$ is a common choice, and is the one that we adopt here. The FCM algorithm requires that the number of clusters, $c$, be specified in advance, and in view of the sample size in our study (and the empirical findings of Giles and Draeseke, 2003) we have considered $c=2,3$ and 4. The algorithm then comprises the following steps:

1. Select the initial locations of the cluster centres.

2. Generate a (new) partition of the data by assigning each data-point to its closest cluster centre.

3. Calculate new cluster centres from the revised partition of the data.

4. If the cluster partition is stable then stop. Otherwise go to step 2 above. 
In the case of fuzzy the memberships, the Lagrange multiplier technique generates the following expression for the membership values to be used at step 2 above:

$$
u_{i k}=1 /\left\{\sum_{j=1}^{n}\left[\left(d_{i k}\right)^{2} /\left(d_{j k}\right)^{2}\right]^{1 /(m-1)}\right\} .
$$

If the memberships of data-points to clusters are 'crisp' then

$$
\begin{aligned}
& u_{i k}=0 ; \quad \forall i \neq j, \\
& u_{j k}=1 ; \mathrm{j} \quad \text { s.t. } d_{j k}=\min .\left\{d_{i k}, \mathrm{i}=1,2, \ldots ., c\right\} .
\end{aligned}
$$

The updating of the cluster centres at step 3 above is obtained via the expression

$$
v_{i}=\left[\sum_{k=1}^{n}\left(u_{i k}\right)^{m} x_{k}\right] /\left[\sum_{k=1}^{n}\left(u_{i k}\right)^{m}\right] ; i=1,2, \ldots, c .
$$

The fixed-point nature of this problem ensures the existence of a solution in a finite number of steps. When the centres of the fuzzy clusters have been determined, each of the $n$ data-points can be allocated to the cluster whose center it is closest to.

\section{Fuzzy Regression Analysis}

To begin with, consider the simple case where there is a single regressor (other than, perhaps, a constant intercept). The fuzzy relationship to be estimated is of the form:

$$
y=f(x)+\varepsilon
$$

where the form of the functional relationship remains unspecified (but will typically involve unknown parameters), and $\varepsilon$ is a random disturbance term. There is no need to make any distributional assumptions about the latter. If the disturbance has a zero mean, the fuzzy function represents the conditional mean of the dependent variable, $y$. To this extent, the framework is the same as that which is adopted in non-parametric kernel regression.

The identification and estimation of the fuzzy model then proceeds according to the following steps: 
Step 1: $\quad$ Partition the sample observations for $x$ into $c$ fuzzy clusters, using the FCM algorithm. This generates the membership values for each $x$-value with respect to each cluster, and also defines a corresponding partition of the data for $y$.

Step 2: $\quad$ Using the data for each fuzzy cluster separately, fit the models:

$$
y_{i j}=f_{i}\left(x_{i j}\right)+\varepsilon_{i j} \quad ; j=1, \ldots ., n_{i} ; i=1, \ldots ., c
$$

In particular, if the chosen estimation procedure is parametric least squares, then

$$
y_{i j}=\beta_{i 0}+\beta_{i 1} x_{i j}+\varepsilon_{i j} \quad ; j=1, \ldots, n_{i} ; i=1, \ldots ., c
$$

Step 3: $\quad$ Model and predict the conditional mean of $y$ using:

$$
\hat{y}_{k}=\left[\sum_{i=1}^{c}\left(b_{i 0}+b_{i 1} x_{k}\right) u_{i k}\right] /\left[\sum_{i=1}^{c} u_{i k}\right] ; k=1, \ldots ., n
$$

where $u_{i k}$ is the degree of membership of the $k^{\text {th }}$ value of $x$ in the $i$ th. fuzzy cluster, and $b_{i m}$ is the least squares estimator of $\beta_{i m}(m=0,1)$ obtained using the $i^{\text {th }}$ fuzzy partition of the sample.

The fuzzy predictor of the conditional mean of $y$ is a weighted average of the linear predictors based on the fuzzy partitioning of the explanatory data, with the weights (membership values) varying continuously through the sample. This latter feature enables non-linearities to be modelled effectively. In addition, it can be seen that the separate modelling over each fuzzy cluster involves the use of fuzzy logic of the form 'IF the input data are likely to lie in this region, THEN this is likely to be the predictor of the output variable", etc.. The derivative of the conditional mean with respect to the input variable also has this weighted average structure, and the same potential for non-linearity.

Note that this modelling strategy is essentially a semi-parametric one. The parametric assumptions could be relaxed further by using kernel estimation to fit each of the cluster submodels at Step 2 above, in which case the estimated derivatives (rather than coefficients) would be weighted at Steps 3 and 4, instead of the parameter estimates. However, some experimentation with this variation of the modelling methodology was undertaken by Giles and Draeseke (2003), and was found not to perform well. 
More generally we will be interested in models that have more than one regressor:

$$
y=f\left(x_{1}, x_{2}, \ldots \ldots, x_{p}\right)+\varepsilon
$$

Assuming a linear least squares basis for the analysis for expository purposes, the steps in the above fuzzy modelling procedure are extended as follows :

Step 1': $\quad$ Separately partition the n sample observations for each $x_{r}$ into $c_{r}$ fuzzy clusters (where $r=1,2, \ldots . p$ ), using the FCM algorithm. This generates the membership values for each observation on each $x$ variable with respect to each cluster.

Step 2': $\quad$ Consider all $c$ possible combinations of the fuzzy clusters associated with the $p$ input variables, where

$$
c=\prod_{r=1}^{p} c_{r}
$$

and discard any for which the intersections involve negative degrees of freedom $\left(n_{r}<p\right)$. Let the number of remaining cluster combinations be $c^{\prime}$.

Step 3': $\quad$ Using the data for each of these $c^{\prime}$ fuzzy clusters separately, fit the models:

$$
y_{i j}=\beta_{i 0}+\beta_{i 1} x_{1 i j}+\beta_{i 2} x_{2 i j}+\cdots \cdots+\beta_{i p} x_{p i j}+\varepsilon_{i j} \quad ; j=1, \ldots ., n_{i} ; i=1, \ldots ., c^{\prime}
$$

Step 4': $\quad$ Model and predict the conditional mean of $y$ by using:

$$
\hat{y}_{k}=\left[\sum_{i=1}^{c^{\prime}}\left(b_{i 0}+b_{i 1} x_{1 k}+\cdots \cdots+b_{i p} x_{p k}\right) w_{i k}\right] /\left[\sum_{i=1}^{c} w_{i k}\right] \quad ; k=1, \ldots ., n
$$

where

$$
w_{i k}=\prod_{r=1}^{p} \delta_{i j} u_{r j k} \quad ; \quad i=1, \cdots \cdots, c^{\prime}
$$


Here, $\delta_{i j}$ is a 'selector' that chooses the membership value for the $j^{\text {th }}$ fuzzy cluster (for the $r^{\text {th }}$ input variable) if that cluster is associated with the $i^{\text {th }}$ cluster combination $\left(i=1,2, \ldots ., c^{\prime}\right)$; and $b_{i m}$ is the least squares estimator of $\beta_{i m}$ obtained by using the $i^{\text {th }}$ fuzzy partition of the sample.

Comparing these steps with those in the case of a single input variable, it is clear that the computational burden associated with the fuzzy modelling increases at the same rate as in the case of multiple linear regression as additional explanatory variables are added to the model. Under some very mild conditions, it can be shown that the fuzzy regression estimator is weakly consistent, and more importantly its rate of convergence is the same as that for the least squares estimator. That is, we have $T^{1 / 2}$ convergence under standard assumptions. In contrast, nonparametric kernel regression suffers from the well-known 'curse of dimensionality' - it converges in probability increasingly slowly as the number of regressors grows. (Strictly speaking, this is true only if all of the regressors are continuous, rather than discrete, variables see Racine and $\mathrm{Li}, 2003$, for details.) 


\section{References}

Akaike, H. (1973), "Information Theory and an Extension of the Maximum Likelihood Principle”, in B. N. Petrov and F. Csáki (eds.), $2^{\text {nd }}$ International Symposium on Information Theory (Akadémiai Kiadó, Budapest), 267-281.

Andreoni, J. and A. Levinson (1998), "The Simple Analytics of the Environmental Kuznets Curve", NBER Working Paper 6739, National Bureau of Economic Research, Cambridge MA.

Bousquet, A. and P. Favard (2000), "Does S. Kuznets' Belief Question the Environmental Kuznets Curve?", mimeo., Université des Sciences Sociales Toulouse.

Clark, H. (2001), "Ruminant Methane Emissions: A Review of the Mrhodology Used for National Inventory Estimations", A Report Prepared for the Ministry of Agriculture and Forestry, New Zealand.

DeBenedictis, L.F. and D.E.A. Giles (1998), "Diagnostic Testing in Econometrics: Variable Addition, RESET, and Fourier Approximations", in A. Ullah and D.E.A. Giles (eds.), Handbook of Applied Economic Statistics (Marcel Dekker, New York), 383-417.

DeBenedictis, L.F. and D.E.A. Giles, 1999, "Robust Specification Testing in Regression: The FRESET Test and Autocorrelated Disturbances", Journal of Quantitative Economics, 15, 67-75.

De Bruyn, S. M., J. C. J. M. van den Bergh and J. B. Opschoor (1998), "Economic Growth and Emissions: Reconsidering the Empirical Basis of Environmental Kuznets Curves", Ecological Economics, 25, 161-175.

Deininger, K. and L. Squire (1998), "New Ways of Looking at Old Issues", Journal of Development Economics, 57, 259-87.

Dijkgraaf, E. and H. R. J. Vollebergh (2001), “A Note on Testing for Environmental Kuznets Curves”, OCFEB Research Memorandum 0102, Research Center for Economic Policy, Erasmus University Rotterdam.

Dickey, D. A. and W. A. Fuller (1979), "Distribution of the Estimators for Autoregressive Time Series With a Unit Root”. Journal of the American Statistical Association, 74, 427-31.

Dickey, D. A. and W. A. Fuller (1981), "Likelihood Ratio Statistics for Autoregressive Time Series With a Unit Root”. Econometrica, 49, 1057-72.

Dickey, D. A. and S. E. Said (1981), “Testing $\operatorname{ARIMA}(\mathrm{p}, 1, \mathrm{q}) \operatorname{Against} \operatorname{ARMA}(\mathrm{p}+1, \mathrm{q})$ )" Proceedings of the Business and Economic Statistics Section, American Statistical Association, 28, 318-22. 
Donovan, K. and L. Baldwin (1999), "Results of the AAMOLLY Model Runs for the Enteric Fermentation Model", mimeo., University of California, Davis.

Egli, H. (2001), "Are Cross-Country Studies of the Environmental Kuznets Curve Misleading? New Evidence From Time Series Data for Germany", Discussion Paper 10/2001, ErnstMoritz-Arndt University of Greifswald.

Ekins, (1997), “The Kuznets Curve for the Environment and Economic Growth: Examining the Evidence", Environment and Planning A, 29, 805-830.

Eviews (2002), Eviews 4.1, User's Guide. (Quantitative Micro Software, Irvine, CA.)

Franses, P. H. (2001), "How to Deal With Intercept and Trend in Practical Cointegration Analysis?", Applied Economics, 33, 577-579.

Giles, D. E. A. (2001), “Output Convergence and International Trade: Time-Series and Fuzzy Clustering Evidence for New Zealand and Her Trading Partners, 1950-1992", Econometrics Working Paper EWP0102, Department of Economics, University of Victoria.

Giles, D. E. A. (2002), "Spurious Regressions With Time-Series Data: Some Further Asymptotic Results", Econometrics Working Paper EWP0203, Department of Economics, University of Vic toria.

Giles, D. E. A. and R. Draeseke (2003), "Econometric Modelling Using Pattern Recognition via the Fuzzy c-Means Algorithm”, in D. E. A. Giles (ed.), Computer-Aided Econometrics (Marcel Dekker, New York), 407-450.

Giles, D. E. A. and H. Feng (2003), “Testing for Convergence in Measures of 'Well-Being' in Industrialized Countries", Econometrics Working Paper EWP0303, Department of Economics, University of Victoria.

Giles, D. E. A., J. A. Giles and E. B. M. McCann (1992), "Causality, Unit Roots and Export-Led Growth: The New Zealand Experience", Journal of International Trade and Economic Development, 2, 195-218.

Granger, C. W. J. and P. Newbold (1974), "Spurious Regressions in Econometrics, Journal of Econometrics, 2, 111-120.

Greasley, D. and L. Oxley (2000), Measuring New Zealand's GDP 1865-1933: A Cointegration-

Based Approach", Review of Income and Wealth, 46, 351-368.

Grossman G. M. and A. B. Krueger (1993), "Environmental Impacts of a North American Free Trade Agreement", in P. Garber (ed.), The U.S.-Mexico Free Trade Agreement. MIT Press, Cambridge MA, 165-177. 
Grossman, G. M. and A. B. Krueger (1995), "Economic Growth and the Environment”, Quarterly Journal of Economics, 110, 353-357.

Harbargh, W., A. Levinson and D. Wilson (2002), "Reexamining the Empirical Evidence for an Environmental Kuznets Curve", Review of Economics and Statistics, 84, 541-551.

Hilton, F. G. H. and A. Levinson (1998), "Factoring the Environmental Kuznets Curve: Evidence From Automotive Lead Emissions", Journal of Environmental Economics and Management, 35, 126-141.

Holtz-Eakin, H. and T. M. Selden (1995), "Stoking the Fires? $\mathrm{CO}_{2}$ Emissions and Economic Growth", Journal of Public Economics, 57, 85-101.

Hornok, Attila and Larsson, Rolf. "The Finite Sample Distribution of the KPSS Test." Econometrics Journal 3 (2000): 108-21.

Jacobsen, P. W. F. and D. E. A. Giles (1998), "Income Distribution in the United States: Kuznets' Inverted-U Hypothesis and Data Non-Stationarity", Journal of International Trade and Economic Development, 7, 405-423.

Jarque, C. and A. Bera (1980), "Efficient Tests for Normality, Homoskedasticity and Serial Independence of Regression Residuals, Economics Letters, 6, 255-259.

Johansen, S. (1988), "Statistical Analysis of Cointegration Vectors", Journal of Economic Dynamics and Control, 12, 231-254.

Johansen, S. (1995), Likelihood-Based Inference in Cointegrated Vector Autoregressive Models (Oxford University Press, Oxford).

Kuznets, S. (1955), "Economic Growth and Income Inequality”, American Economic Review, 45, $1-28$.

Kwiatkowski, D., P. C. B. Phillips, P. Schmidt, and Y. Shin (1992), "Testing the Null Hypothesis of Stationarity Against the Alternative of a Unit Root." Journal of Econometrics, 54, 91-115.

MacKinnon, J. G. (1991), “Critical Values for Co-integration Tests”, in R. F. Engle and C. W. J. Granger (eds.), Long-Run Economic Relationships (Cambridge University Press, Cambridge), 267-276.

Maddison, A. (1995), Monitoring the World Economy, 1820-1992 (Organisation for Economic Co-operation and Development, Paris).

Mosk, C. A. (2003), Bound for Distant Lands: Trade and Migration in the Modern World, book manuscript.

New Zealand Ministry of Agriculture and Forestry (2000), International Trade Statistics, Wellington, New Zealand. 
New Zealand Ministry of Agriculture and Forestry (2002), Agriculture, Forestry and Horticulture in Brief, Wellington, New Zealand.

New Zealand Ministry of Agriculture and Forestry (2003), Livestock Data, as reported on the internet at <http://www.maf.govt.nz/statistics/primaryindustries/livestock/>

New Zealand National Institute of Water and Atmospheric Research (2003), Environmental Performance Indicators Program, as reported on the internet at <www.environment.govt.nz/indicators/climate/methane.html>

Ogwang, T. (1994), "Economic Development and Income Inequality: A Nonparametric Investigation of Kuznets' U-Curve Hypothesis", Journal of Quantitative Economics, 10, 139-153.

Perman, R. and D. I. Stern (1999), "The Environmental Kuznets Curve: Implications of NonStationarity", Working Papers in Ecological Economics 9901, Centre for Resource and Environmental Studies, Australian National University, Canberra.

Pfaff, A. S. P., S. Chaudhuri and H. L. M. Nye (2001), "Why Might One Expect Environmental Kuznets Curves? Examining the Desirability and Feasibility of Substitution", mimeo., Columbia University.

Phillips, P. C. B. (1986), "Understanding Spurious Regressions in Econometrics, Journal of Econometrics, 33, 311-340.

Racine, J. and Q. Li (2003), "Nonparametric Estimation of Regression Functions With Both Categorical and Continuous Data", forthcoming in Journal of Econometrics.

Ruspini, E. (1970), “Numerical Methods for Fuzzy Clustering”, Information Science, 2, 319-350.

Roca, J., E. Padilla, M. Farré and V. Galletto (2001), "Economic Growth and Atmospheric Pollution in Spain: Discussing the Environmental Kuznets' Curve Hypothesis", Ecological Economics, 39, 85-99.

Schmalensee, R., T. M. Stoker and R. A. Judson (1998), "World Carbon Dioxide Emissions: 1950-2050", Review of Economics and Statistics, 80, 15-27.

Schwarz, G. (1978), "Estimating the Dimension of a Model”, Annals of Statistics, 6, 461-464.

Selden, T., and D. Song (1994), "Environmental Quality and Devlopment: Is There a Kuznets Curve for Air Pollution Emissions?", Journal of Environmental Economics and Management, 28, 147-162.

Selden, T, and D. Song (1995), "Neoclassical Growth, the JCurve for Abatement, and the Inverted U-Curve for Pollution", Journal of Environmental Economics and Management, 29, 162-168. 
Shafik, N. (1994), "Economic Development and Environmental Quality: An Econometric Analysis", Oxford Economic Papers, 46, 757-773.

Shafik, N. and S. Bandyopadhyay (1992), Economic Growth and Environmental Quality: Time Series and Cross Country Evidence. Background paper for World Development Report 1992, World Bank, Washington, DC.

SHAZAM (2001), SHAZAM Econometrics Package, User's Guide, Version 9 (Northwest Econometrics, Vancouver, B.C..)

Shepherd, D. and F. K. C. Shi (1998), "Economic Modelling With Fuzzy Logic", paper presented at the CEFES '98 Conference, Cambridge, U.K..

Statistics New Zealand (1998), Hot Off the Press (June Quarter), available on the internet at <http://www.stats.govt.nz/domino/external/pasfull/pasfull.nsf/web/Hot+Off+The+Press +Gross+Domestic+Product+June+1998+quarter?open>

Stern, D. I. and M. S. Common (2001), "Is There an Environmental Kuznets Curve for Sulfur?", Journal of Environmental Economics and Management, 41, 162-178.

Stern, D. I., M. S. Common and E. B. Barbier (1997), "Economic Growth and Environmental Degradation: The Environmental Kuznets Curve and Sustainable Development", World Development, 24, 1151-1160.

Stock, J. H. (1987), “Asymptotic Properties of Least-Squares Estimators of Co-integrating Vectors", Econometrica, 55, 1035-1056.

Stokey, N. L. (1998), “Are There Limits to growth?”, International Economic Review, 39, 1-31.

Stroomer, C., and D. E. A. Giles (2003), "Income Convergence and Trade Openness: Fuzzy Clustering and Time Series Evidence", Econometric Working Paper EWP0304, Department of Economics, University of Victoria.

Summers, R. and A. Heston (1995), The Penn World Table, Version 5.6 (National Bureau of Economic Research: Cambridge MA).

Taskin, F. and O. Zaim (2000), "Searching for a Kuznets Curve in Environmental Efficiency Using Kernel Estimation", Economics Letters, 68, 217-223.

Ulyatt, M. J., K. R. Lassey, I. D. Shelton and C. F. Walker (2002), "Methans Emission From Dairy Cows and Wether Sheep Fed Subtropical Grass-Dominant Pastures in Midsummer in New Zealand", New Zealand Journal of Agricultural Research, 45, 227-234.

Utt, J. A., W. W. Hunter and R. E. McCormick (2001), "On the Relation Between Net Carbon Emissions and Income. Carbon Sinks Global Warming: Are Rich People Cool?’. Mimeo., Department of Economics, Washington State University.

World Bank (1992), World Development Report 1992. Oxford University Press, New York. 
Zadeh, L. A. (1965), "Fuzzy Sets”, Information and Control, 8, 338-353.

Zadeh, L. A. (1987), Fuzzy Sets and Applications: Selected Papers. Wiley, New York. 


\section{Footnotes}

* We are extremely grateful to Dr Harry Clark (AgResearch Ltd., New Zealand) and Dr Gerald Rys (Ministry of Agriculture and Forestry, New Zealand) for helpful correspondence and the provision of data and technical information relating to the scientific research program into enteric methane emissions in that country.

1. Total atmospheric methane concentrations in New Zealand rose from 1669.5 ppb in 1990 to $1736.3 \mathrm{ppb}$ in 2000 (in terms of $\mathrm{Gg}$ of $\mathrm{CO}_{2}$-equivalent units). See New Zealand National Institute of Water and Atmospheric Research (2003).

2. See Clark, 2001.

3. This level was just over 73 million $\mathrm{CO}_{2}$-equivalent tonnes.

4. Some of this research has been undertaken in collaboration with other scientific teams in Australia and France.

5. See Table 1 below for details of the different enteric methane emission rates associated with the different animal types.

6. See New Zealand Ministry of Agriculture and Forestry (2000).

7. See New Zealand Ministry of Agriculture and Forestry (2002). This represented a reduction from over $48 \%$ in 1992 . Agriculture as a whole accounted for $53.8 \%$ of the value of New Zealand's exports in 1999, and forestry products accounted for approximately an additional $11 \%$ of export dollars.

8. It also seems likely that the results of some of the earlier studies, using time-series data, may have been affected by a failure to take account of the fact that these data were nonstationary. For some evidence on this point, see Jacobsen and Giles (1998) Perman and Stern (1999), and Stern and Common (2001).

9. Special issues of Ecological Economics (in 1995 and 1998), and Environment and Development Economics (1996) have been devoted to the environmental Kuznets curve.

10. See Selden and Song (1995, p.147).

11. Each GHG has its own 'global warming potential', set by the Intergovernmental Panel on Climate Control (IPCC). In the case of methane this is 21 (c.f., $\mathrm{CO}_{2}=1$ ) for a 100-year time-horizon.

12. These are constant 1999 dollars.

13. Although Stern and Common (2001) have data for sulfur emissions for the period 1850 to 1990, their EKC study is based on models estimated for 1960 to 1990 due to constraints on the availability of PPP-adjusted international GDP data. 
14. Our data for livestock numbers end in 1996, due to a change in the reporting method. Official Ministry of Agriculture and Fisheries (now Forestry) figures for the period prior to 1971 are taken from the annual New Zealand Yearbooks.

15. Recent confidential work by Clarke and Ulyatt deals with updates to these estimates. No emission rate estimates are available for the period prior to 1990, the latter year being the 'base year' for New Zealand's Kyoto Protocol obligations. In our calculations, in the absence of contrary evidence, we assume a constant emission rate for each animal type over time.

16. The series using the '1990-High' and '1999-Low' emission estimates are visually indistinguishable.

17. A 'spurious regression' arises when the data are non-stationary, but are not cointegrated, and the associated results are meaningless (and increasingly so as the sample size increases). See Granger and Newbold (1974), Phillips (1986) and Giles (2002) for more details.

18. It is understood, of course, that this turning point may occur at a level of output that is outside the range of the sample values, so it may not be 'observed'.

19. Their modelling framework is based, in turn, on the earlier contribution of Shephard and Shi (1998).

20. It should be emphasized that while this technique may appear to be similar to spline analysis, in fact it is quite different, and is much more flexible. In spline analysis the joinpoints (or 'knots') for the continuous sections of the function are taken as known and are specified in advance. In fuzzy regression, the FCM algorithm determines the partition of the data into the clusters on the basis of the sample values. Moreover, in fuzzy regression the different estimated cluster results are mixed' by using the estimated degrees of membership, whereas in spline analysis the separate functional sections are simply abutted to one another.

21. The following discussion is taken essentially from Giles and Draeseke (2003, pp.412419). For some additional applications of fuzzy clustering in economic applications, see Giles (2001), Giles and Feng (2003) and Stroomer and Giles (2003).

22. For a more complete discussion of this topic, see Zadeh (1987).

23. The FCM algorithm is usually attributed to Ruspini (1970), though there are now many variants of it in use. 
24. Applying the tests to the differenced data confirmed that none of the series are $\mathrm{I}(2)$. In addition, allowing for the possibility of structural breaks in the trends of the data did not affect our conclusions.

25. Details of the results obtained by using each of the other three methane series are available from the authors on request. The results that we present here are completely insensitive to the choice of the $\mathrm{CH}_{4}$ series.

26. If ' $\mathrm{T}$ ' denotes the sample size, a super-consistent estimator is one that converges to the true parameter value at a rate ' $\mathrm{T}$ ', rather than the usual rate of ' $\mathrm{T}$ '1/2, See Stock (1987).

27. The FRESET test of Debenedictis and Giles $(1998,1999)$ is similar to Ramsey's RESET test, but a Fourier series approximation is used in its construction, rather than a polynomial approximation. This use of a global (rather than local) approximation increases the power of test markedly, even in the context of contamination from serial correlation. The FRESET test can be conducted with the DIAGNOS command in the SHAZAM econometrics package.

28. In Figure 3(a) we present the 'fitted values' from the OLS regressions, plotted against GDP. The relationships shown in Figure 3(b) are obtained when we solve for the longrun estimated relationship, as follows. If the model is of the generic form, $\mathrm{y}_{\mathrm{t}}=\mathrm{a}+\mathrm{b} \mathrm{x}_{\mathrm{t}}+\mathrm{c} \mathrm{y}_{\mathrm{t}-1}+\mathrm{u}_{\mathrm{t}}$, then $\mathrm{y}^{*}=\left(\mathrm{a}^{*}+\mathrm{b}^{*} \mathrm{x}\right) /\left(1-\mathrm{c}^{*}\right)$, where an asterisk denotes an estimated value.

29. Giles and Draeseke (2003) estimate a conventional Kuznets' curve for the U.S.A. using fuzzy regression, as one of their illustrative examples. Nonparametric (kernel) estimates of Kuznets' curves are surprisingly unusual. For conventional Kuznets' curves see Ogwang (1994) and Jacobsen and Giles (1998); and for the only nonparametric EKC that we are aware of, see Taskin and Zaim (2000).

30. The same is true when the fuzzy analysis is conducted with $c=4$. In this case the higher of the two maxima occurs at a real (1990 dollars) per capita output level of NZ\$11,680 (US\$8,433), which corresponds to the year 1971 in our sample. Of course it may also be possible to achieve a 'double-hump' EKC with a higher-order polynomial specification, but we have not pursued this further.

31. The New Zealand economy boomed during the Korean War, largely as a result of the increased demand for its coarse-grade wool.

32. See Mosk (2003) for further details.

33. The export of live sheep is to countries in the Middle East, so that religious customs may be observed during slaughtering. 
34. New Zealand's production was 258 kilo-tonnes of fleece and skin wool (greasy wool equivalent). The productions of Australia and China were 652 and 291 kilo-tonnes respectively. See the British Wool Marketing Board's site on the internet at <http://www.britishwool.org.uk/a-factsheet4.asp>

35. The simple correlations with $\mathrm{CH}_{4} 90 \mathrm{~L}$ are -0.026 and -0.018 when wool prices are deflated by the CPI and by export prices respectively.

36. Using Penn World Table data, the real (1990 dollars) per capita GDP's for New Zealand, China, South Africa and Uruguay in 2000 were approximately $\$ 16,750, \$ 3,200, \$ 6,700$ and $\$ 8,600$. Our preferred EKC peaks at approximately $\$ 8,140$.

37. This research has been undertaken primarily by the LandcareResearch, Agresearch and HortResearch organizations. For more information on the internet, see <http://www.landcareresearch.co.nz/research/greenhouse/climatechange/methane.asp> 